\title{
Caracterização clínica e epidemiológica das leishmanioses em cães no Estado de São Paulo
}

\author{
Clinical and epidemiological characterization of leishmaniasis in dogs in São Paulo State
}

\author{
Cauê Pereira TOSCANO루 ; Claudio Nazaretian ROSSI ${ }^{1}$; Vítor Márcio RIBEIRO²; Márcia Dalastra \\ LAURENTI $^{3}$; Carlos Eduardo LARSSON ${ }^{1}$
}

\author{
${ }^{1}$ Departamento de Clínica Médica da Faculdade de Medicina Veterinária e Zootecnia da \\ Universidade de São Paulo, São Paulo - SP, Brasil \\ ${ }^{2}$ Pontifícia Universidade Católica Minas, Betim - MG, Brasil \\ ${ }^{3}$ Laboratório de Investigações Médicas (LIM-50) do Departamento de Patologia da Faculdade de Medicina da \\ Universidade de São Paulo, São Paulo - SP, Brasil
}

\begin{abstract}
Resumo
Caracterizou-se retrospectivamente, a partir do ano de 1997 até março de 2008, a ocorrência de casos de leishmaniose, visceral ou tegumentar, dentre os cães dermatopatas atendidos em serviço especializado de hospital-escola veterinário de Faculdade de Medicina Veterinária e Zootecnia da Universidade de São Paulo. Para o diagnóstico em 427 animais, foram utilizados testes sorológicos (Ensaio Imunoenzimático Indireto, Imunofluorescência Indireta e/ou Fixação de Complemento), parasitológicos diretos e moleculares (Reação em Cadeia da Polimerase), que resultaram na confirmação de $117(27,4 \%)$ casos positivos. Da amostragem, $96(82,1 \%)$ eram cães de raça definida, os demais $21(17,9 \%)$ não dispunham de plena definição racial, sendo $57(48,7 \%)$ fêmeas e $60(51,3 \%)$ machos. Quanto à faixa etária, 26 (22,2\%) apresentavam idade inferior a 36 meses, $48(41 \%)$ entre 36 e 84 meses e $43(36,8 \%)$ ultrapassavam o sétimo ano de vida. Considerou-se 64 (54,7\%) cães como oligossintomáticos, 44 (37,6\%) sintomáticos e os nove (7,7\%) remanescentes como assintomáticos. As principais alterações clínicas observadas foram, em ordem decrescente, lesões tegumentares, linfonodomegalia, anemia, disorexia, prostração e esplenomegalia. Quanto às alterações hematológicas, a mais importante foi a linfopenia relativa e absoluta. Dos animais positivos para a enfermidade, 96 (82,1\%) correspondeu a casuística alóctone ao Município de São Paulo.
\end{abstract}

Palavras-chave: Leishmaniose. Cão. Epidemiologia. Diagnóstico.

\begin{abstract}
The occurrence of visceral or cutaneous canine leishmaniasis cases among dermatophatic dogs admitted to the veterinary teaching hospital School of Veterinary Medicine and Animal Husbandry - University of São Paulo from 1997 to 2008 was retrospectively characterized. For the diagnosis of 427 animals, serological (Enzyme-Linked Immunosorbent Assay, Indirect Immunofluorescence and/or Complement Fixation), parasitological and molecular (Polymerase Chain Reaction) tests were performed, which resulted in 117 (27.4\%) confirmed positive cases. Of these, 96 (82.1\%) were pure breed dogs and the others 21 (17.9\%) were cross breed, being 57 (48.7\%) females and 60 (51.3\%) males. In terms of age, $26(22.2 \%)$ were younger than 36 months, 48 (41\%) were between 36 and 84 months, and $43(36.8 \%)$ were older than seven years old. Sixty-four $(54.7 \%)$ dogs were considered oligosymptomatic, $44(37.6 \%)$ symptomatic, and the remaining nine $(7.7 \%)$ asymptomatic. The main clinical findings were, in descending order, dermal lesions, lymphadenopathy, anemia, dysorexia, prostration and splenomegaly. As for hematological disorders, relative and absolute lymphopenia was the most important findings. Ninety-six $(82.1 \%)$ of the positive animals correspond to allochthonus cases from São Paulo municipality.
\end{abstract}

Keywords: Leishmania sp. Dog. Epidemiology. Diagnosis.

\section{Introdução}

A leishmaniose é uma antropozoonose causada por diversas espécies de protozoários do gênero Leishmania. No Brasil, a transmissão da leishmaniose é efetuada por vetores do gênero Lutzomyia, em especial L. longipalpis ${ }^{1}$. Estes insetos possuem hábitos alimentares crepusculares e noturnos e

\section{Correspondência para:}

Prof. Dr. Carlos Eduardo Larsson

Av. Prof. Dr. Orlando Marques de Paiva, 87, Cidade Universitária,

São Paulo, SP, Brasil. CEP: 05508-270

e-mail: larsderm@usp.br

Recebido: 08/02/12

Aprovado: 02/04/13

Estudo fomentado pela Fundação de Amparo à Pesquisa do Estado de São Paulo (FAPESP), sob a forma de bolsa de Iniciação Científica (Número do processo: 2007/04764-4). 
raramente se movem a mais de um quilômetro de distância do seu local de procriação. Dessa forma, é notória a importância da existência e mobilidade de hospedeiros, que atuam como reservatórios do protozoário, para a disseminação da doença de per se, sendo responsáveis, na última década, pela progressiva urbanização e detecção da doença em áreas reputadas como não endêmicas.

$\mathrm{Na}$ América do Sul, fatores como o clima, o desmatamento e a adaptação do vetor ao ambiente tem contribuido para a manutenção da região como área endêmica. Tais condições, somadas ao grande número de cães domésticos (Canis familiaris), considerados como os principais reservatórios da doença ${ }^{2}$, criam uma situação de constante possibilidade de infecção. Assim sendo, é patente o risco de infecção pelos hospedeiros que visitem ou residam em áreas endêmicas. Além disso, é importante ressaltar que os animais infectados poderão agir como agentes disseminadores da doença, caso migrem para locais não-endêmicos nos quais exista o inseto vetor.

$\mathrm{O}$ presente estudo visou à determinação de possíveis focos endêmicos de leishmaniose em municípios do Estado de São Paulo, além de buscar sua caracterização epidemiológica. Tais resultados permitirão, pressupostamente, inferir a situação de risco da Capital paulista e de seus arredores, no que diz respeito à existência e ao potencial de disseminação desta zoonose parasitária.

\section{Material e Método}

Foi efetuado o levantamento retrospectivo de 427 prontuários dos casos clínicos com suspeita de acometimento por leishmaniose canina (visceral ou tegumentar), dentre aqueles atendidos no Serviço de Dermatologia do Departamento de Clínica Médica (VCM) e do Hospital Veterinário (HOVET) da FMVZ/USP, sendo avaliados os prontuários dos casos atendidos a partir de 1997, ano este em que se evidenciou o primeiro caso alóctone de Leishmaniose Visceral Canina (LVC) no Estado de São Paulo, até março de 2008. Desses prontuários, foram separados 117 com diagnóstico positivo estabelecido.

Dos 21 animais caracterizados como positivos para leishmanioses, atendidos de 1997 a até meados de 2006, 66,7\% dos diagnósticos foram estabelecidos pelos resultados de provas sorológicas (Ensaio Imunoenzimático Indireto - ELISA, Reação de Imunofluorescência Indireta - RIFI e/ou Fixação de Complemento) realizadas no Departamento de Parasitologia do Instituto de Ciências Biomédicas (ICB) da Universidade Federal de Minas Gerais (UFMG). Os 14 animais $(66,7 \%)$ considerados como sorologicamente positivos o eram em mais de uma das técnicas. Outros 33,3\% tiveram o diagnóstico complementado por meio de exames parasitológicos executados a partir de biópsias de pele, citologia aspirativa de linfonodos e medula óssea ou pela realização da Reação em Cadeia da Polimerase (PCR), realizados no Laboratório Paulista de Dermatopatologia ou no Serviço de Laboratório de Análises Clínicas do HOVET da FMVZ/USP.

Os animais sob suspeição de parasitismo, atendidos entre meados de 2006 e março de 2008 tiveram, na sua totalidade, o diagnóstico estabelecido a partir da evidenciação sorológica da presença de anticorpos anti-Leishmania chagasi, obtida pela prova de ELISA efetuada com antígeno bruto total, no Laboratório de Investigações Médicas (LIM-50) da Faculdade de Medicina da Universidade de São Paulo (FM/USP). $\mathrm{O}$ ponto de corte da reação correspondeu à somatória da média acrescida de três desvios padrões da população de cães de área inendêmica, excluindo-se aqueles soros que estavam muito próximos ao ponto de corte (10\% acima). O teste ELISA, empregado para a identificação dos casos positivos em cerca de 92,3\% da amostragem (108 casos) ao longo do período considerado, permitiu que se assegurasse a acurácia do diagnóstico sorológico ${ }^{3}$. Ressalte-se que poucos 
foram os animais $(25,6 \%$ - 30 animais) submetidos concomitantemente ao diagnóstico parasitológico e pela PCR, até por decisão contrária por parte dos proprietários dos cães, que consideravam o processo de colheita doloroso e invasivo, mormente nos casos em que animal apresentava sintomas vagos e, sob sua óptica, pouco preocupantes.

Quando da confirmação de positividade, buscou-se a caracterização dos seguintes parâmetros: (1) eventuais locais de infecção (municípios, estados ou país de origem, local de residência ou de deslocamento transitório (viagens), como "fins de semana", "férias" ou "a trabalho ou lazer"); (2) perfil do animal infectado (definição racial, sexo, idade); (3) aspectos sintômato-lesionais; (4) resultados dos exames complementares solicitados.

Os animais positivos foram classificados segundo as categorias de "portadores assintomáticos", "oligossintomáticos" (um a três sintomas) ou "sintomáticos" (mais de três sintomas), segundo a classificação utilizada por Mancianti et al. ${ }^{4}$.

O teste de Qui-Quadrado foi o utilizado para verificar a existência de uma possível associação entre a positividade dos animais com a definição racial, sexo ou idade. Por outro lado, a análise das frequências dos grupos de animais "oligossintomáticos", "sintomáticos" e "assintomáticos" foi efetuada com o Teste de proporção para uma amostra. O teste de diferença de proporções entre duas amostras foi aplicado para determinar a significância estatística da maior ou menor frequência das diferentes alterações clínicas, lesões cutâneas e resultados dos exames complementares evidenciados nos animais positivos para a leishmaniose.

\section{Resultados, Discussão e Conclusões}

Afora os $117(27,4 \%)$ casos que se apresentaram como positivos e os 301 (70,5\%) negativos, em nove animais $(2,1 \%)$ os resultados obtidos não foram conclusivos em face de resultados de títulos, pela RIFI, ou de densidades ópticas, no ELISA, muito próximas ao ponto de corte.

Dos animais positivos, $96(82,1 \%)$ eram cães de raça definida e $21(17,9) \%$ não apresentavam definição racial, sendo que não foi comprovada significância estatística $(\mathrm{p}=0,368)$ no que tange a uma maior suscetibilidade dos animais com padrão racial definido (CRD) ou sem (SRD) raça definida, podendo a diferença de frequência observada ser resultante de maior demanda de donos de cães CRD ao HOVET/USP ou, ainda, ao fato de, supostamente, a condição econômica destes proprietários ser melhor que aquela dos criadores de SRD, propiciando maiores possibilidades de exposição ao vetor quando de viagens (lazer, férias) a áreas de foco ou, finalmente, estar relacionada a um maior e melhor acesso aos cuidados médico-veterinários.

Igualmente, não foi percebida diferença estatisticamente significativa $(\mathrm{p}=0,213)$ quanto à prevalência de leishmanioses entre os animais positivos segundo o sexo. Destes, 57 (48,7\%) eram fêmeas e 60 (51,3\%) machos. Sendo assim, pôde-se inferir que a Lutzomyia longipalpis realiza o repasto sanguíneo de forma aleatória, sendo a prevalência da infecção ou doença dependente da proporção de machos e fêmeas na população de cada região. Resultados semelhantes foram descritos por Sobrino et al. ${ }^{5}$ para populações de lobos (Canis lupus) e raposas (Vulpes vulpes) acometidas pela leishmaniose.

$\mathrm{Na}$ análise de faixa etária quando da confirmação de positividade à infecção ou doença, também não foi constatada a existência de diferença estatisticamente significativa $(\mathrm{p}=0,526)$, sendo que $26 \quad(22,2 \%)$ apresentavam idade inferior aos 36 meses, 48 (41\%) entre 36 e 84 meses e $43(36,8 \%)$ com idade superior a estas. Apesar de se observar uma aparente maior frequência de acometimento dos animais adultos e senectos, é mister que se destaque que, insolitamente, não se dispõe de assentamentos, em série histórica de anos, da distribuição por faixa etária dos animais 
que demandam o HOVET/USP anualmente (cerca de 48.000 casos anuais). Tal fato impossibilita uma análise mais precisa dos percentís ora evidenciados.

Os resultados coligidos e analisados, também, mostraram que a boa parte dos animais positivos (54,7\% - 64 animais) apresentava de um a três sintomas (oligossintomáticos). Na sequência, respectivamente, $37,6 \%$ (44 animais) e 7,7\% (nove animais) dos cães leishmanióticos se constituíam em animais, respectivamente, sintomáticos e assintomáticos. Portanto, foi evidenciada a distribuição dos animais, em ordem decrescente, que os oligossintomáticos prevaleceram sobre os sintomáticos $(\mathrm{p}=0,0001)$ e estes sobre os assintomáticos $(\mathrm{p}<0,0001)$. A baixa proporção de animais assintomáticos encontrada destoa de dados obtidos por Panaro et al. ${ }^{6}$, na Itália, que evidenciaram alta prevalência de animais assintomáticos, que atribuíram possivelmente a uma maior produção de óxido nítrico pelos macrófagos do hospedeiro assintomático, que, Zafra et al. ${ }^{7}$, admitiram ter um importante papel no controle do parasitismo, agindo como um fator leishmanicida endógeno sobre as formas amastigotas presentes no organismo. Porém, esta disparidade de resultados pode decorrer, eventualmente, do fato da amostragem, do presente estudo, ter sido coligida de prontuários de cães provenientes do atendimento em hospital veterinário-escola, ou seja, alguns foram levados ao HOVET/USP justamente por manifestarem alguns dos sintomas da protozoose.

Em oposição, os proprietários de animais portadores assintomáticos não buscam atendimento especializado, tendo em vista que desconhecem a enfermidade de per se, sua evolução e, portanto, a ocorrência do estado de portador, impedindo a cabal e real representatividade amostral. Pode-se, ainda, pressupor que a ênfase dada em um hospital-escola à realização de acurada e detalhada anamnese leva à identificação de manifestações sintomáticas vagas, despercebidas pelos proprietários, mas obtidas pela inquirição. Merece evidente destaque o percentil de menos de $8 \%$ de assintomáticos, pois estes, somados àqueles que não se soroconvertem ${ }^{8}$ constituem-se em reais fontes de infecção aos vetores e, por conseguinte, aos animais e seres humanos. Todavia, a partir dos percentís de infecção detectados, em animais oligo (54,7\%) e assintomáticos (7,7\%), quiçá deva ser realizada com maior frequência, pelos médicos veterinários, a busca da comprovação do diagnóstico da leishmaniose.

De todos os animais que se mostraram positivos pelos exames executados foi notório o grande número daqueles acometidos por lesões de pele $(81,2 \%)$, seguidos pelos linfonodomegálicos (56,4\%), anêmicos (25,6\%), disoréticos (23\%), prostrados (21,4\%) e esplenomegálicos (17,9\%), evidenciando que o quadro leishmaniótico que os acometia estava, praticamente, sempre associado a alterações cutâneas. Dentre as alterações cutâneas observadas, foi evidenciada uma maior ocorrência de lesões relacionadas às perdas e reparações teciduais (74,4\%), alterações de cor (63,2\%) e alopecia $(53,8 \%)$. Ressalte-se que o diagnóstico foi estabelecido a partir de casuística provinda de tradicional serviço de atendimento dermatológico veterinário, o que, de forma óbvia, aclara o percentual de alterações tegumentares evidenciadas.

A alta ocorrência de alterações tegumentares observada no presente estudo é uma característica comum dos cães acometidos pela leishmaniose, sendo compatível com o descrito por Ciaramella et al. ${ }^{9}$, em 150 cães naturalmente infectados pela $L$. chagasi, no qual descreveram a detecção de "dermatite seca esfoliativa" (56\% dos animais), úlceras (40\%) e alopecia periorbital (18\%) ou difusa (14\%), e, ainda, com o descrito em clássico tratado de infectologia ${ }^{10}$. De forma semelhante, Marcondes et al. ${ }^{11}$ (2000) relataram a observação de alterações dermatológicas (queda de pêlos, lesões ulcerativas, prurido intenso, pelame baço e quadro disqueratinizante ou seborréico) em $68 \%$ dos 215 cães com leishmaniose visceral estudados no 
município de Araçatuba, São Paulo. Assim, de forma sintética, deve-se estar alerta, quando da execução dos exames físico e dermatológico propriamente dito, ao fato de que boa parte dos animais acometidos pelo protozoário possa apresentar alterações tegumentares classificadas como perdas e reparações (escamas, crostas), discromias (vásculo-sanguíneas ou pigmentadas), formações sólidas ou alterações de espessura (pápulas, nódulos, ceratose) e alopecias.

A linfonodomegalia, de alta ocorrência $(56,4 \%)$ nos animais do presente estudo, também é comumente descrita em levantamentos clínicos pretéritos sobre a leishmaniose. Giunchetti et al. ${ }^{12}$, além de evidenciarem altos índices de linfonodomegalia nos cães leishmanióticos, realizaram a avaliação histopatológica dos linfonodos de tais animais demonstrando que as reações retratadas por hiperplasia/hipertrofia do tecido linfóide foram as mais frequentemente encontradas nos animais assintomáticos, ao passo que nos sintomáticos já era observada uma atrofia da zona cortical dos linfonodos, possivelmente decorrente de uma ação mais agressiva ou prolongada das amastigotas da $L$. chagasi.

Outras alterações bem evidenciadas no presente estudo, em distintos percentís, tais como anemia e palidez de mucosas, disorexia (hipo ou anorexia) com perda de peso, prostração, esplenomegalia, poliúria/ polidipsia (PU/PD), hepatomegalia, onicogrifose e oftalmopatias também foram evidenciadas.

De fato a anemia pode ser provocada pela lise de eritrócitos, perda sanguínea ou devido a uma hipo ou aplasia medular ${ }^{13,14}$.

Almeida et al. $^{15}$ descreveram a esplenomegalia, hepatomegalia, onicogrifose e nefropatias, levando, estas últimas, às poliúria e polidipsia.

Ciaramella et al. ${ }^{9}$ observaram como sendo bastante comum, em animais acometidos pela leishmaniose, alterações ungueais (onicogrifose) e oculares (epífora, ceratoconjuntivite seca, uveíte, panoftalmite), lesões renais seguidas de falência renal grave do órgão e anemia. Tais diferenças também foram relatadas por Greene $^{10}$ e Marcondes ${ }^{8}$ como sendo características da infecção pela Leishmania chagasi. A onicogrifose, sempre tão ressaltada, juntamente com a caquexia e a cifose da coluna vertebral, nas ilustrações de compêndios clínicos e de parasitologia, nos capítulos sobre leishmanioses, assim como em diversas pesquisas, foi evidenciada em pouco mais de $10 \%$ dos casos. Isto pode retratar o estado pouco avançado da evolução clínica da protozoose na casuística atendida, mas, também, que a onicogrifose não é sintoma tão patognomônico como se decanta.

A alteração mais encontrada, nos exames complementares dos cães positivos frente à leishmaniose, foi a linfopenia, corroborando o descrito por Greene ${ }^{10}$. Observações, ora evidenciadas, tais como monocitose, anemia, eosinofilia, hipoalbuminemia (com hiperproteinemia e hiperglobulinemia) e trombocitopenia também têm sido amplamente descritas. Keenan et al. ${ }^{16}$ verificaram a presença de anemia, trombocitopenia, hiperproteinemia (com hipoalbuminemia e hiperglobulinemia) em cães da raça Pastor Alemão inoculados com amastigotas de Leishmania chagasi ou Leishmania donovani. Marcondes ${ }^{8}$ descreveu quadro semelhante em relação às alterações na concentração das proteínas séricas, relatando que a hiperglobulinemia evidenciada decorre de um acentuado aumento da fração gamaglobulínica (com uma leve diminuição da fração alfaglobulina). Almeida et al. ${ }^{15}$ relataram hiperproteinemia (com hipoalbuminemia e hiperglobulinemia) em animais naturalmente infectados, além da existência de quadros renais (glomerulonefrite e consequente insuficiência renal decorrentes da deposição glomerular de complexos antígeno-anticorpo), também descritos por Ciaramella et al. ${ }^{9}$ e Greene ${ }^{10}$. Estes quadros são, possivelmente, responsáveis por alterações, tais como as evidenciadas no presente 
estudo, a exemplo do aumento exacerbado dos níveis de uréia no sangue e da proteinúria.

Quanto às localidades referidas, nas quais os animais, com diagnóstico positivo, provavelmente se infectaram, observou-se uma ampla distribuição por cidades do interior e litoral do Estado de São Paulo, além de cidades de outros oito Estados da Federação (MG, RJ, PR, BA, SC, CE, RS e MA). Dentre as localidades evidenciadas, merecem destaque as cidades de Cotia/SP (11 animais positivos - 9,4\%), Guarujá/SP (nove positivos - 7,7\%), Ibiúna/SP (sete positivos - 6\%), Embu/SP (cinco positivos - 4,3\%), Itanhaém/SP (cinco positivos - 4,3\%), Belo Horizonte/MG (cinco positivos - 4,3\%), Atibaia/SP (quatro positivos - 3,4\%), Bertioga/ SP (quatro positivos - 3,4\%) e Caraguatatuba/SP (quatro positivos - 3,4\%) pelo maior número de animais positivos que nelas podem ter adquirido a protozoose. A distribuição cartográfica, no Estado de São Paulo, das localidades referidas durante a anamnese é apresentada na figura 1 .

A identificação das localidades de origem ou de deslocamento dos animais com vagos e não patognomônicos sintomas e lesões, suscitada por indagação de eventual deslocamento do domicílio, mormente quando este se localiza em área sabidamente indene, levou a solicitação de exames sorológicos e de outros complementares. Portanto, o percentil de $62 \%$, obtido pela somatória de animais oligo e assintomáticos, foi estabelecido pela simples inclusão de questionamento relativo ao deslocamento do paciente. Deve-se ressaltar que a simples pergunta “o animal viaja?” muitas vezes é respondida com uma negativa, pois o "viajar", por vezes, não é assim considerado quando se trata de deslocamentos a municípios adjacentes e próximos à Capital ou a Grande São Paulo. Deve, então, o clínico estar atento e acostumar-se a incluir, rotineiramente, a indagação no bojo da anamnese.
Afora os $21(17,9 \%)$ cães em que não se pôde caracterizar adequadamente, quando da anamnese, o deslocamento geográfico ou a origem do paciente canino, mormente devido ao recebimento a título de doação, "aquisição" em feiras de adoção, achado do animal em vias ou praças públicas, nos demais 96 $(82,1 \%)$ foi identificado o eventual local de infecção. Assim, pode-se afirmar que o percentual de $82,1 \%$ de casos diagnosticados corresponde, inequivocamente, a uma casuística alóctone ao Município de São Paulo, onde sabidamente inexiste a presença do vetor Lutzomyia.

Não foi possível a aplicação de um teste estatístico para a comparação das frequências das cidades de provável aquisição da protozoose citadas e coligidas durante as anamneses, tendo em vista que não pôde ser caracterizada uma independência entre as localidades, já que um único cão poderia ser considerado em mais de uma cidade, seja de origem, moradia ou estada transitória, devido a ocorrência de deslocamentos a mais de uma cidade relacionada ao mesmo animal. Por isso, apenas foi considerada a frequência, de per se, como parâmetro para a avaliação dos possíveis focos de leishmanioses.

Os centros de controle de zoonoses municipais do Estado de São Paulo e os demais órgãos relacionados ao controle de endemias das Secretarias (Estadual e Municipal) vinculadas à saúde pública devem ser alertados sobre a casuística distribuída pelo Estado, além da maior concentração na região centroleste (ao redor da Capital) e litoral, observando as localidades de onde, aparentemente, proveio o maior número de casos de infecção protozoótica, para que sejam implementadas medidas de conscientização de moradores, turistas (férias, finais de semana) e adquirentes de animais (canis comerciais, nas nefastas "feiras-de-cães") e para que se adotem medidas preventivas (combate sistêmico dos vetores, controle do fluxo de cães, telagem, recolhimento dos cães no crepúsculo, utilização de coleiras repelentes, 


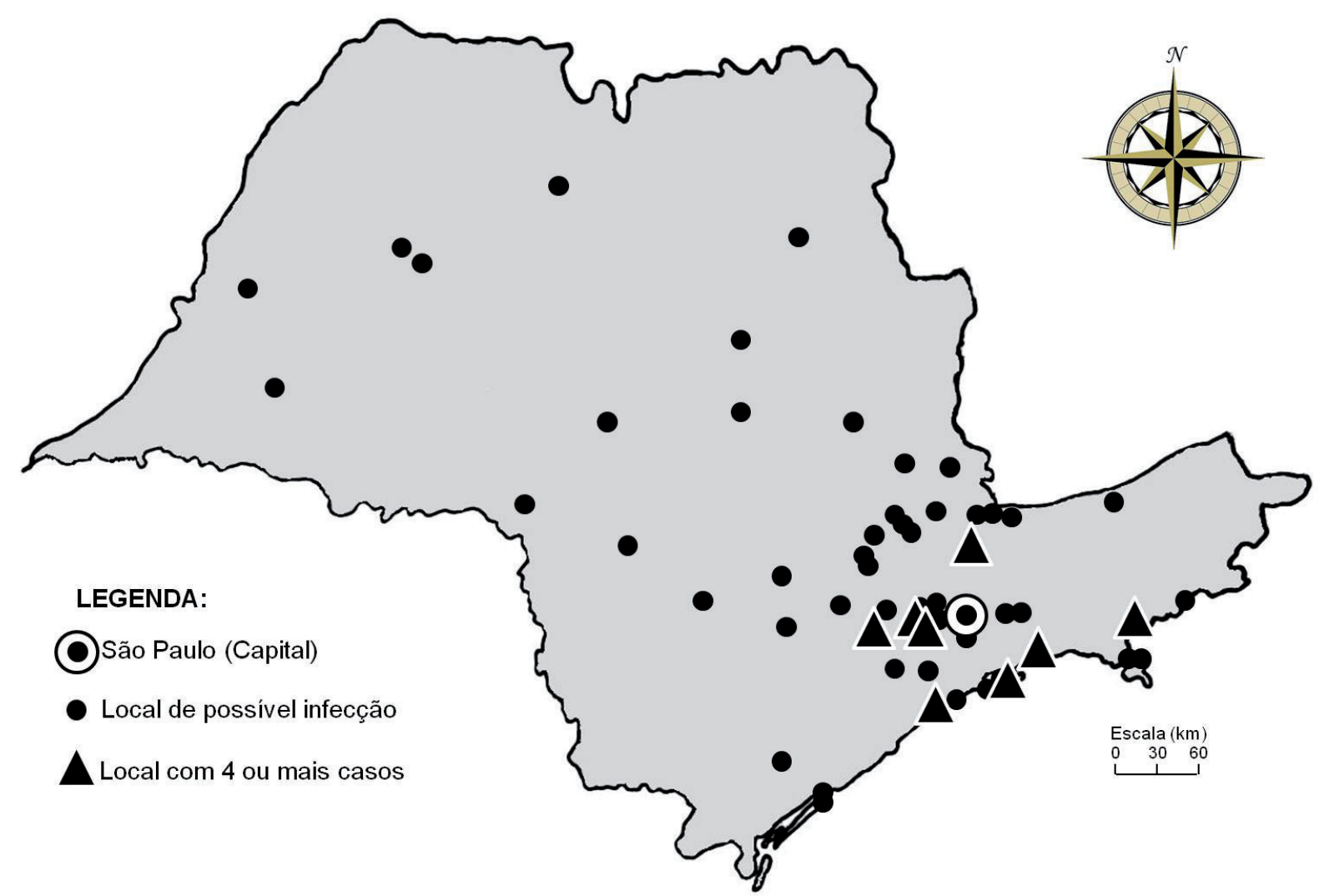

Figura 1 - Distribuição dos casos de leishmaniose canina evidenciados no Estado de São Paulo, no período de 1997 a 2008, no Serviço de Dermatologia do VCM-HOVET/ USP, segundo a distribuição de municípios paulistas potenciais fontes de infecção - São Paulo - 2011

manutenção de flora repelente, sistemática coleta de lixo, dentre outras) e não tão somente o sacrifício de cães associado à proibição do tratamento de cães hígidos e supostamente infectados. É mister que se ressalte que a postura federal implementada (Portaria Interministerial No 1.426 , de 11 de Julho de
2008), que impede a terapia dos animais acometidos pelas leishmanioses, acarrete a não permissão do diagnóstico etiológico por parte dos seus proprietários, que evitarão a todo custo sacrificar seus cães ou com eles desaparecendo dos hospitais, clínicas e ambulatórios veterinários. 


\section{Referências}

1. BAUZER, G.; SOUZA, N. A.; MAINGON, R. D.; PEIXOTO A. A. Lutzomyia longipalpis in Brazil: a complex or a single species? A mini-review. Memorias do Instituto Oswaldo Cruz, v. 102, n. 1, p. 1-12, 2007.

2. MAIA, C.; NUNES, M.; CRISTÓVÃO, J.; CAMPINO, L. Experimental canine leishmaniasis: clinical, parasitological and serological follow-up. Acta Tropica, v. 116, n. 3, p. 193-199, 2010.

3. MARCONDES, M.; BIONDO, A. W.; GOMES, A. A.; SILVA, A. R.; VIEIRA, R. F.;CAMACHO, A. A.; QUINN, J.; CHANDRASHEKAR, R. Validation of a Leishmania infantum ELISA rapid test for serological diagnosis of Leishmania chagasi in dogs. Veterinary Parasitology, v. 175, n. 1-2, p. 15-19, 2011.

4. MANCIANTI, F.; GRAMICCIA, M.; GRADONI, L.; PIERI, S. Studies on canine leishmaniasis control 1. Evolution of infection of different clinical forms of canine leishmaniasis following antimonial treatment. Transactions of the Society Royal of Tropical Medicine and Hygiene, v. 82, n. 4, p. 56-57, 1988.

5. SOBRINO, R.; FERROGLIO, E.; OLEAGA, A.; ROMANO, A.; MILLAN, J.; REVILLA, M.; ARNAL, M. C.; TRISCIUOGLIO, A.; GORTÁZAR, C. Characterization of widespread canine leishmaniasis among wild carnivores from Spain. Veterinary Parasitology, v. 155, n. 3-4, p. 198-203, 2008.

6. PANARO, M. A.; BRANDONISIO, O.; DE CAPRARIIS, D.; CAVALLO, P.; CIANCIULLI, A.; MITOLO, V.; OTRANTO, D. Canine leishmaniasis in Southern Italy: a role for nitric oxide released from activated macrophages in asymptomatic infection? Parasites and Vectors, v. 1, n. 1, p. 10, 2008.

7. ZAFRA, R.; JABER, J. R.; PÉREZ-ECIJA, R. A.; BARRAGÁN, A.; MARTINEZ-MORENO, A.; PÉREZ, J. High iNOS expression in macrophages in canine leishmaniasis is associated with low intracellular parasite burden. Veterinary Immunology and Immunopathology, v. 123, n. 3-4, p. 353-359, 2008.

8. MARCONDES, M. Envolvimento do sistema nervoso central na leishmaniose visceral canina. 2009. $174 \mathrm{f}$. Tese (Livre-Docência) - Faculdade de Odontologia, Universidade Estadual Paulista Júlio de Mesquita Filho, Araçatuba, SP.
9. CIARAMELLA, P.; OLIVA, G.; LUNA, R. D.; GRADONI, L.; AMBROSIO, R.; CORTESE, L.; SCALONE, A.; PERSECHINO, A. A retrospective clinical study of canine leishmaniasis in 150 dogs naturally infected by Leishmania infantum. Veterinary Record, v. 141, n. 21, p. 539-543, 1997.

10. GREENE, C. E. Infectious diseases of the dog and cat - Revised reprint. 3. ed. Philadelphia: W. B. Saunders, 2006. 1424 p.

11.FEITOSA, M. M.; IKEDA, F. A.; LUVIZOTTO, M. C. R.; PERRI, S. H. V. Aspectos clínicos de cães com leishmaniose visceral no município de Araçatuba - SP (Brasil). Clínica Veterinária, v. 5, n. 28, p. 36-44, 2000.

12. GIUNCHETTI, R. C.; MARTINS-FILHO, A. O.; CARNEIRO, C. M.; MAYRINK, W.; MARQUES, M. J.; TAFURI, W. L.; CORRÊA-OLIVEIRA, R.; REIS, A. B. Histopathology, parasite density and cell phenotypes of the popliteal lymph node in canine visceral leishmaniasis. Veterinary Immunology and Immunopathology, v. 121, n. 1-2, p. 23-33, 2008.

13.BANETH, G. Leishmaniasis. In: GREENE, C. E. Infectious diseases of the dog and cat - Revised reprint. 3 ed. Philadelphia: W. B. Saunders, 2006. p. 685-698.

14.KOUTINAS, A. F.; POLIZOPOULO, Z. S.; SARIDOMICHELAKIS, $\quad M$. N.; ARGYRIADIS, D.; FYTIANOU, A.; PLEVRAKI, K. G. Clinical considerations on canine visceral leishmaniasis in Greece: a retrospective study of 158 cases (1989-1996). Journal of the American Animal Hospital Association, v. 35, n. 5, p. 376-383, 1999.

15. ALMEIDA, M. A.; JESUS, E. E.; SOUSA-ATTA, M. L.; ALVES, L. C.; BERNE, M. E.; ATTA, A. M. Clinical and serological aspects of visceral leishmaniasis in northeast Brazilian dogs naturally infected with Leishmania chagasi. Veterinary Parasitology, v. 127, n. 3-4, p. 227-232, 2005.

16. KEENAN, C. M.; HENDRICKS, L. D.; LIGHTNER, L.; WEBSTER, H. K.; JOHNSON, A. J. Visceral leishmaniasis in the German sheperd dog. I. Infection, clinical disease, and clinical pathology. Veterinary Parasitology, v. 21, n. 1, p. 74-79, 1984. 